\title{
A Cyberphysical System Based Mass-Customization Approach with Integration of Industry 4.0 and Smart City
}

\author{
Mehmet Karaköse and Hasan Yetiş \\ Department of Computer Engineering, Firat University, Elazı̆̆, Turkey \\ Correspondence should be addressed to Hasan Yetiş; h.yetis@firat.edu.tr
}

Received 31 March 2017; Revised 24 July 2017; Accepted 6 August 2017; Published 30 August 2017

Academic Editor: Danda B. Rawat

Copyright (C) 2017 Mehmet Karaköse and Hasan Yetiş. This is an open access article distributed under the Creative Commons Attribution License, which permits unrestricted use, distribution, and reproduction in any medium, provided the original work is properly cited.

\begin{abstract}
Smart city is a city which is designed to meet the people's demands. In addition to use of sources efficiently, trends of people are also a need that smart city should meet. Buying personalized products in a cheap and fast way is a demand of people of today. Mass customization, which is defined as the personalization of products, achieves making the tailor-made products cheaper. In this study, we propose a new approach for mass customization with the integration of smart retail and smart production. With removing the operators and actualizing the progress autonomously, it is aimed to reduce the waiting time of customers. Because less waiting time means that there are more mass-customization customers, and this is expected to increase the popularity of mass customization. Thus, reducing wastes and increasing productivity are aimed. This study also constitutes the infrastructure that enables a production system to autonomously perform all stages from order to delivery. With the given scenarios, challenges and advantages of desired approach are discussed.
\end{abstract}

\section{Introduction}

Smart city is relatively new and developing concept among the other city concepts such as talented city, wired city, and ecocity. Because it contains a part of other city concepts, smart city is a wide concept [1]. That is why it is possible to encounter various smart city projects in different types and fields, and it is difficult to make a specific smart city definition [2]. In general, the smart city is a city equipped with methods which are developed to meet increasing population needs more effectively and efficiently [3]. The world has become a very crowded place with an increase in population, so crowded countries such as China have developed some measures for population limitation. The management of city resources that remain constant or limited over the growing population has become very important. These resources not only are natural sources such as air, energy, and terrain but also are human-generated sources such as roads, parking areas, and buildings. Furthermore, the needs do not always arise from the necessity; the things that people desire are also a need. So, smart city should meet the demands of people. Minimizing human factor and making work easy are among the main subjects and needs of humanity since the first era. Technology has evolved in this way.

When we look at the development of industry, the first three stages of industrial revolution have actualized by using steam-powered machines, electricity-powered machines, and programmable microprocessors in manufacturing, respectively. Today, 4th industrial revolution which is named Industry 4.0 is actualizing using cyberphysical systems (CPS) in Industry [4]. Industry is a part of city and there are common interests between Industry 4.0 and smart city concepts. They both aim to minimize human interaction and the energy consumption. Industry 4.0 , which aims at totally man-free production, is more energy efficient and more manageable [5]. Common interests of smart city concepts and Industry 4.0 benefits are shown in Figure 1.

In the preindustrial era, the production type was tailormade productions done by skilled craftsmen, which is called craft production. While the industrial revolution and production lines bring together one type of mass production, such special productions continue to exist. However, craft production is not a widely preferred method because the prices are visibly different. A faster and cheaper production 


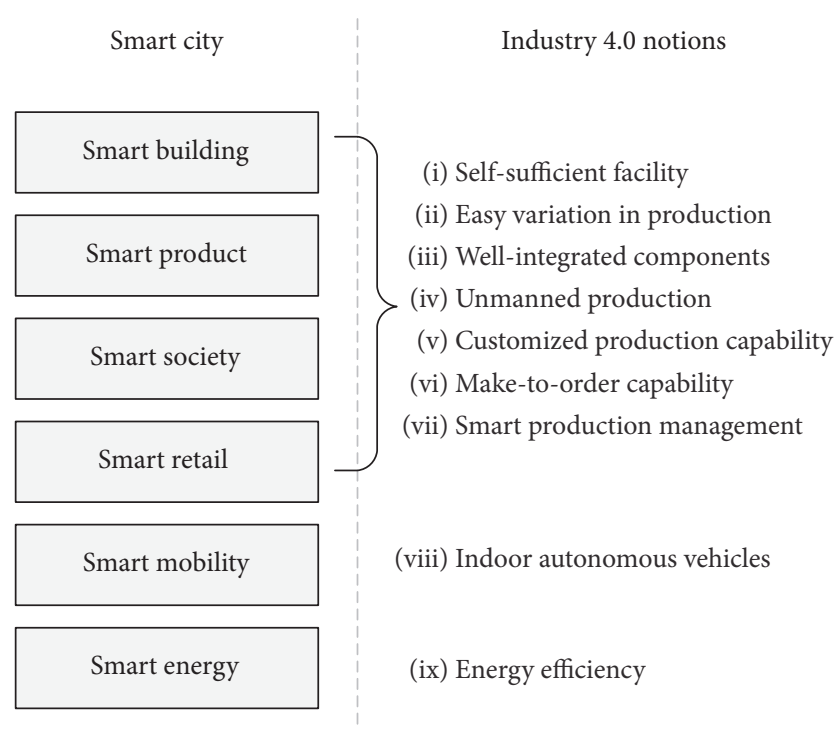

FIGURE 1: Smart city components and their relations with Industry 4.0 notions [6].

model that can produce limited-count different variations of a product, which is called lean production, is introduced after mass production [5]. According to this method transport, inventory, motion, waiting, overprocessing, overproduction, and defects (TIMWOOD) are main sources of wastes in manufacturing and they should be handled for more effective manufacturing. Later, producing customer special products at a cheaper price in the factory environment to meet the customer's needs reveals the concept of mass customization. In summary, after the industrial revolution, mass production, which can produce one type of production, lean production, which enables producing predefined product types with some adjustments on the system within minutes, and mass customization, which is actualized upon the demand of the customers, were brought out. Although it seems impossible to customize production with production bands, it is possible to achieve this with 4 factors. These key factors which make mass customization easy are as follows:

(i) Flexibility

(ii) Connectivity

(iii) Modularity

(iv) Organization

A CPS infrastructure ensures the key factors which are required for mass customization such as flexibility, modularity, and Internet. Furthermore, because it is possible to fix the system with an intervention to the cloud and to check the data in the system, CPS is superior in terms of integration with other systems. So, in order to achieve mass customization, using CPS and Industry 4.0 is a suitable way. Cyberphysical systems consist of three main layers. These are cyber, physical, and communication layers. As the name implies, the physical layer contains sensors that measure physical environment values and actuators that are in contact with the physical environment. In the cyber

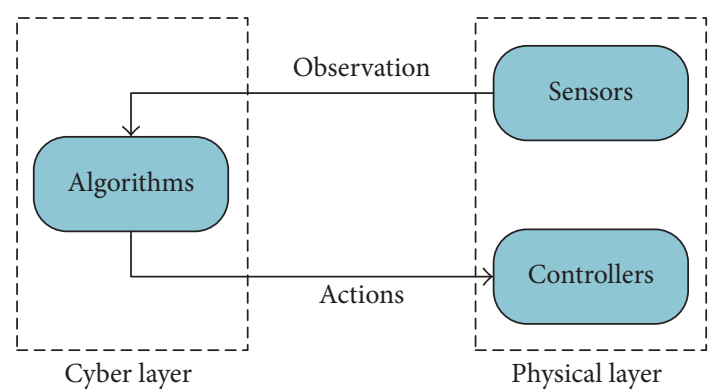

FIgURE 2: Cyberphysical system structure [7].

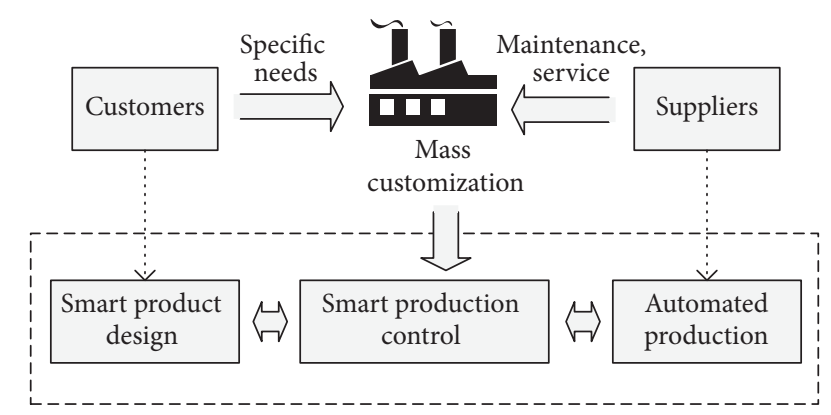

FIGURE 3: The block diagram about actualizing of mass customization.

layer, the data coming from the physical environment are processed and necessary algorithms are created to produce appropriate behavior. Computational operations take place in the cyber layer. The communication layer is responsible for transferring the data from the physical layer to the cyber layer and transferring the commands from the cyber layer to the physical layer. Basic structure of CPS is given in Figure 2.

Mass customization, which forms a part of this study, can be actualized in 3 ways. The first one is the make-tostock method in which a product is manufactured uniformly; then the user can customize the product according to his/her needs. The second one is the assemble-to-order method that is achieved by combining the product's previously produced modules in line in accordance with the customer's request. The last one is the make-to-order method in which the production starts upon customer order. Mass customization allows the production of special products at low cost in terms of color, function, feature, or style. Since the tailormade production requires to carry out the production on order, it removes the problems such as stockpiling, opening a store, or surplus stocks. Because of profitable in terms of customers and producers, it is one of the big trends of today's manufacturing. For these reasons, it is being implemented successfully by the pioneer companies such as Nike, Dell, and Mymuesli. It is also seen possible making special medicine at production line for each patient in near future. A block diagram representing actualizing of mass customization is given in Figure 3.

Although mass customization has advantages, the supply time is also increased compared to the normal products and this partly reduces its attractiveness. For being useful, 


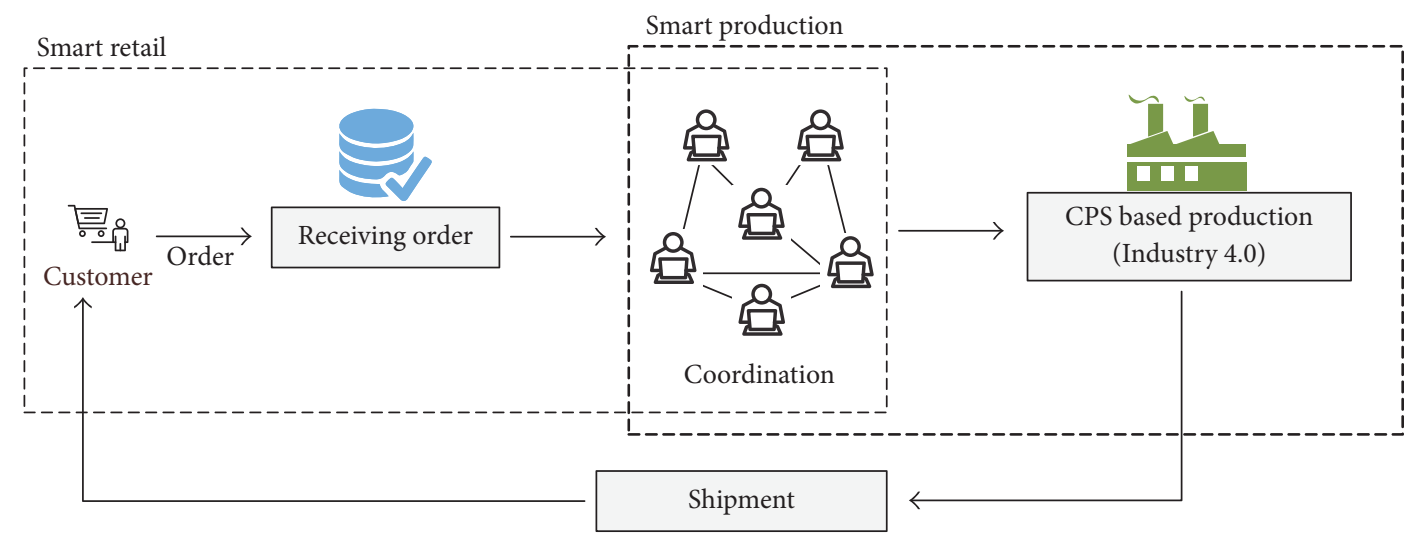

FIGURE 4: Integration of smart retail and Industry 4.0 for mass-customized production.

essentially a customized product should not cost twice or triple the price of a mass-produced item, and it should not take twice as long to receive the customized product either. People of today demand minimizing human interaction, buying tailor-made productions in a cheap way, and actualizing things faster. In this paper a new mass-customization approach is proposed in order to meet the demands of era. The main aim of this study is making the time shorter from order to delivery by minimizing human interaction for mass-customized products. Most of the procurement period goes through the processing of the received order and the adjustment of the configurations. In this study, a method has been proposed to shorten the CPS-based supply period, including smart trade, which is part of Industry 4.0 and Smart City, for mass customization. Cyberphysical systems are an infrastructure that removes the necessity of microcontrollers to be at physical components with the development of Internet technologies. As they are more advantageous than classical embedded systems in terms of flexibility, reliability, and controllability, classical embedded systems have begun to be changed with cyberphysical systems [9].

\section{Materials and Methods}

Buying tailor-made products in a cheap and fast way is a demand of today's people. Cheaper tailor-made products can be produced thanks to the mass customization. This paper aims at reducing the duration of supply of mass customization. Most of the time spent for production is caused by human factor. We proposed an approach that removes the operators between order and production events in order to make the process faster. Internet-aided order-toproduction steps and operators that coordinate order and production steps are shown in Figure 4.

Today, you can perform bank transactions, pay bills, and buy something thanks to the Internet and technology. The Internet removes the need of human factor. Therefore, the scenario is built on online shopping. According to the scenario, user is able to customize his/her production via the Internet as such in current applications. After specialization of his/her product, autocalculated price is offered to customer. If he/she agrees, then payment and order processes are started. When the order delivers to system, it is verified automatically by the application at server, and then it is posted to subsystem which coordinates the totally man-free production aimed factory. So, the operators that coordinate these two systems are removed.

Removing the coordination unit from the system has some challenges. For example, when the coordination is actualized by humans, they can verify that their message is sent successfully. But machines need some more effort to do it. Some precautions should be taken to prevent data loss. Hence, the two subsystems should handshake to confirm that the order is delivered to other system. Basically, the progress of order is as follows. The system takes the order and adds it to process queue. Taking order and adding it to process queue is actualized in one transaction in order to prevent data loss. So, when the order is added to process queue, order status on server, which user can access, is updated. An approximate production date according to queue status is also sent to the server. Any change on production status triggers the server to update; hereby customer can track his/her production status real-time. Furthermore, with use of the process queue, it is possible to give priority to customers who pay more for a faster supply. This method can bring new ways of earning for companies. The basic block diagram of the approach is given in Figure 5.

Figure 5 shows a basic diagram of progress. Dotted squares represent the two different stages which are smart city and Industry 4.0 production environment. The task of order server, which is between smart city and Industry 4.0 environment, is receiving the customized orders through Internet and transfers them to Industry 4.0 environment safely. Diverging the stages makes the system secure, but it brings also synchrony problems together. If any exception occurred in any step, system marks the process as uncompleted, and uncompleted processes are triggered by system at certain intervals. Thus, the system works as a whole and order losses are prevented. In the factory environment, which is dotted rectangle at right in Figure 5, production process is actualized by CPS infrastructure. So, the adjustments for each special product are made by simple changes on software in cyber layer. According to CPS, the data which are obtained by sensors in physical layer are sent to computational tools in 


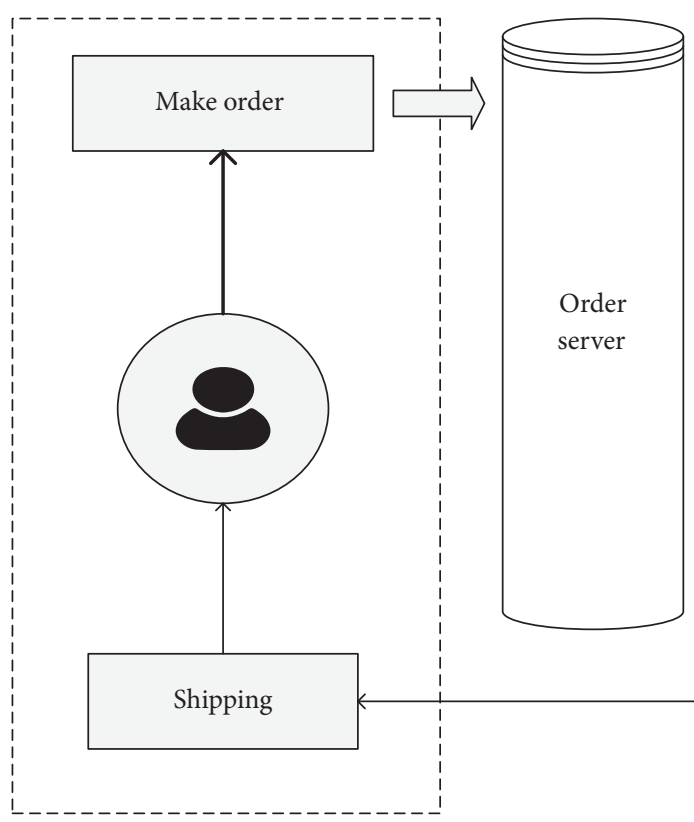

Smart city

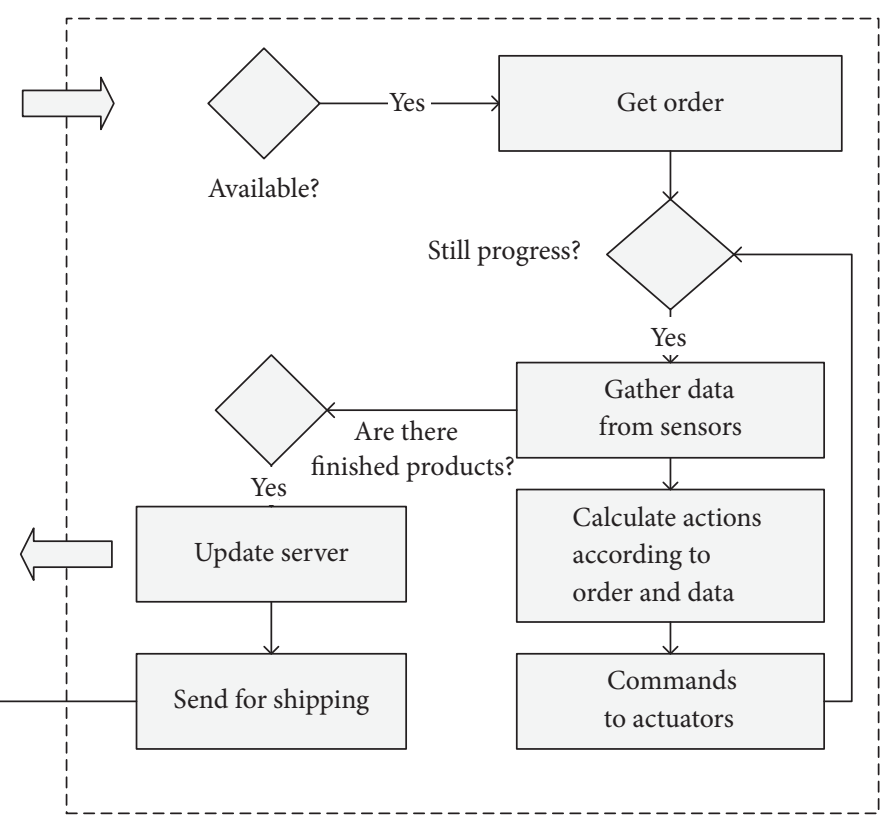

Industry 4.0

FIGURE 5: The basic block diagram of the proposed approach.
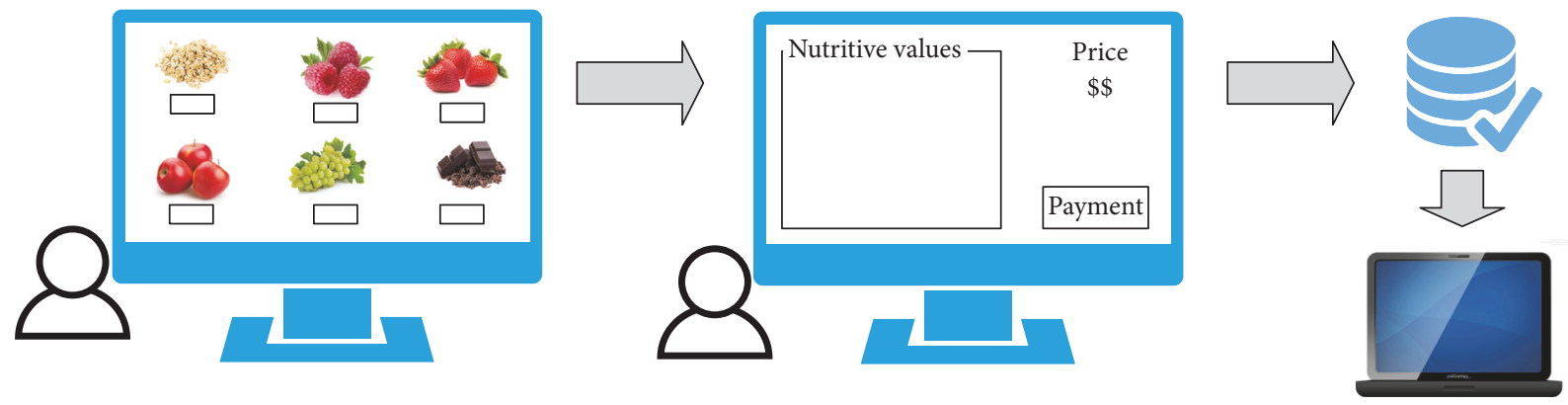

FIGURE 6: Customizing and making payment of crispy.

cyber layer thanks to communication technologies. The cyber layer makes the calculations according to the customer order and the sensor data to produce appropriate commands for machines in physical layer. After the production of product, it is shipped by autonomous vehicles, which is a study field of smart city $[10,11]$. Hereby, the production process from ordering to shipping can be done without any human interaction. For a better understanding of the method, let us consider a firm that produces fruity crispy. For example, there can be raspberries, strawberries, apples, grapes, and chocolate in crispy. Customer is able to determine the amount of fruit and oats. Figure 6 shows the ordering and taking into the request. The request is sent to CPS main processor.

Because of their real-time communication skills, the product is ready to be produced immediately after the order. In CPS structure, the main processor configures the production platform according to orders. For example, consider that there are more than 6 orders in queue. An example situation is given by Figure 7. M0 to M7 are actuators which actualize the given movement. $\mathrm{M} 0$ is for rotation of the production line, M7 is for packaging, and M1-M6 are for setting the amount of fruits. The main computer has the information of all orders to be produced. So, it decides to work of actuator. For example, at the current time shown in Figure 7, $n+3$ th product needs 50 -grams apple, and $n+1$ th product does not need chocolate. So, while M6 is not activated, M4 is made active for some time. If all actuators done their work, then M0 works and the next configuration for production is loaded.

Without the operators, the production is realized. But, such a system brings main two questions, the first one is that how secure is it to connect the factory to Internet; and the second one is that in which cases running the factory is logical, because security and effective task scheduling are crucial for any large system [12].

First, establishing such a system may seem insecure, because when we connect our factory to Internet it becomes vulnerable to attacks from the Internet. An example of this occurred in October 21, 2016, as IOT devices were hacked [13]. There are studies that reduce the effect of such problem in literature [14]. But in fact, there is no real connection between user and the facility network directly in this paper. Customers can access the server which they can make orders and the 


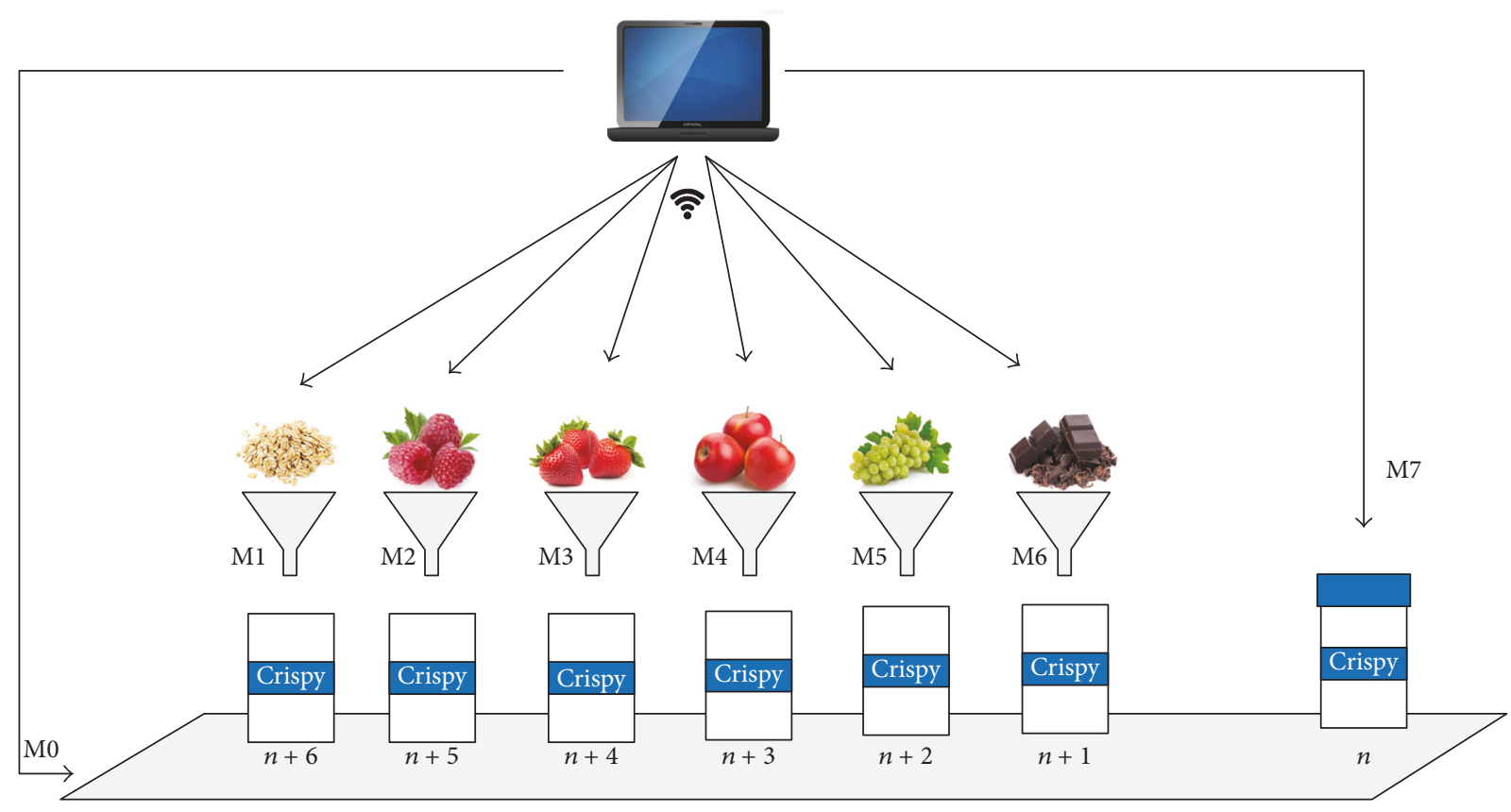

FIGURE 7: A CPS-based crispy production line.

server sends the order only when the order is completed. So, separating the systems which serves customers and the systems which organize the facility makes the system reliable for Internet attacks such as DDOS (distributed denial of service) [15]. The same is true for the customer.

The second problem is working the machines in factory for just a one order or a few orders. Put machines in action may require more energy and starting and stopping them often may cause much more cost. So, when machines are working, the new order is taken to process queue, and when the machines are stopped the new order is taken to waiting queue. If the order is taken while machines are in action, it means that the product will be produced soon. But if the machines are resting, it means that the order should wait for a while for achieving fulfilled condition. A block diagram for new order status is given in Figure 8.

The fulfilled condition depends on the following:

(i) Total waiting order count

(ii) Total waiting time of customers

(iii) The min amount of order for efficient working of machines

(iv) The rate of importance of customer happiness to importance of profit for companies

An algorithm to decide whether running the factory is logical or not can be created with considering the factors above. If the algorithm says it is logical then the machines, which are stopping, are starting to work. The adjustment of the production elements in the factory to the order received will be done in a completely autonomous manner. With integration of assistive technologies, system can also be used by disabled people easily [16]. Using CPS structure makes the system flexible and it also makes the system developable.

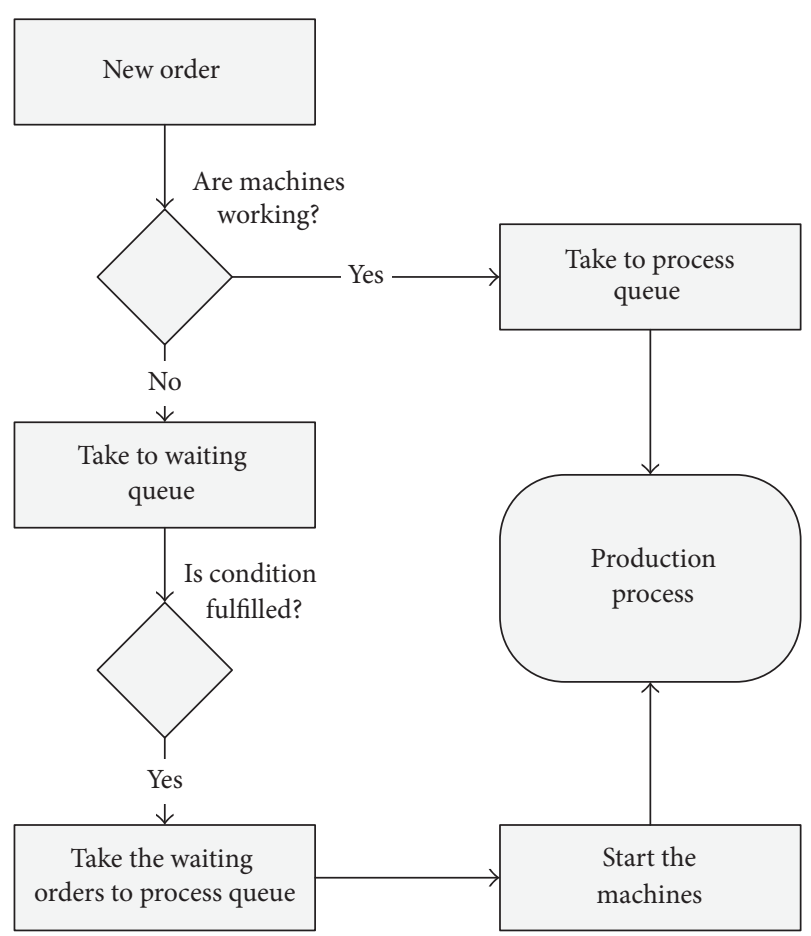

Figure 8: Add new order to queue according to machines status.

\section{Results and Discussion}

Most of the firms estimate their sales and make stock, and they can incur losses due to the overstock. Mass customization, whose production is started after the order, is a new way of manufacturing. Mass customization not only is helpful with firms but also provides personal products to customer. 


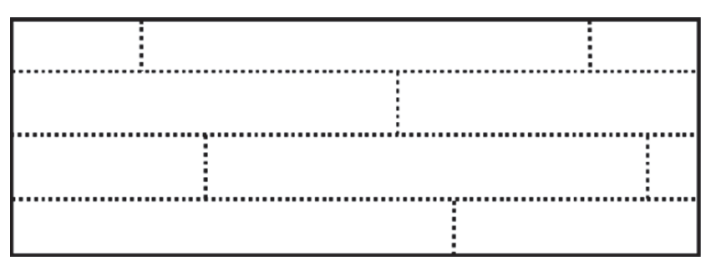

(a)

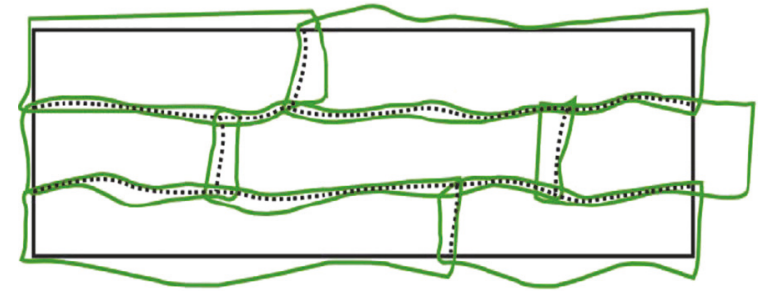

(b)

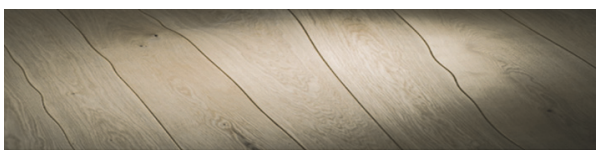

(c)

FIGURE 9: Rectangular floorboards and curved floorboards [8].

So, it is a production method based on win-win relationship. But the extra waiting time for buying personalized product is the biggest problem in front of the mass customization. It is the fact that machines are much faster in specific areas, they programmed. And they are prone to make less mistakes. So, human interaction is a factor which must be minimized in order to achieve faster and more accurate works. Therefore, in this study, we aimed to remove the operators between the order and production steps.

Smart city aims to achieve strong city characteristics such as economy and culture, with more efficient use of the physical infrastructure by using cybercomputations such as artificial intelligence and data analytics [18]. On the other hand, electronic platforms, which are also used for making people more active in choices about city and even country, are utilized in smart city concept [19]. Using such platforms not only make the people life easier but also provide us with data to analyze other components of smart city. So, we use Internet and mobile platforms to taking orders. With the electronically gathered information, some estimates can be done to make the production process more efficient. Furthermore, the information can be used for learning algorithms and selfmodified systems can be achieved [20].

Using Internet and connecting the two different parts make the system faster. Minimizing the human factor makes the system smarter. For example, one of the firms which use smart manufacturing systems is Bolefloor [8]. Bolefloor Company achieved the production of mass customization based novel wooden design products in flexible way. They aim to save raw materials which are cropped while trying to make the floorboards rectangular, and they produce curved shaped floorboards instead of rectangular thanks to the technology they used. A sample floorboard and the raw materials for producing them are given in Figures 9(a) and 9(b), respectively. The visual image of the floorboards with curved edges is given by Figure 9(c).

While the floorboards have to be cropped straight shaped to fit each other in mass production, mass customization has removed this obligation. As seen by Figure 9, raw materials should be cropped to obtain rectangular floorboards. After the cropping process, the cropped raw materials, which is shown by the area of between green and dotted lines in Figure 9(b), turn into trash.

Producing mass-customized floors is more complex than producing rectangular floors because it is hard to assemble nonstraight edged shapes. In order to find the optimal solutions, application software and hardware should work in a harmony. Such a system depends on the similar characteristics with CPS. The block diagram of the process of masscustomized floorboard production is given by Figure 10. The figure shows us that the components of system, both 3rd part software and hardware, work in a tight interaction.

Mass customization is used in manufacturing such as vehicles, mobile devices, clothes, and footwear. It also can be used in eyeglass manufacturing. Eyeglass frames are shaped by warping the materials by machines at same ratio, so the products are limited to few models. Warping process of a frame raw material is given in Figure 11.

But with warping the raw material at different ratios, much more eyeglass models can be produced. With considering a factory which has machines that can produce eyeglass frames with different size, color, shape, and customized text and package, people are able to customize their products through the Internet and the users are supported by order customization applications to make designs suitable to produce. A sample system is given in Figure 12.

The machines in Figure 12 are set up to suit the CPS infrastructure and they can be controlled easily by the main computer in cyber layer. Main computer sends the information of what they do to machines, and machines act according to this information. The new orders which users make are added to order queue in main computer. If the factory is working or the working condition is satisfied, the orders are being produced. If the machines are stopped and the orders in queue do not maintain the working criteria, then the orders wait until the working criteria are satisfied. Working and resting time of facility can be controlled easily in cyber layer. The orders which will be produced are being processed according to algorithms, so, for example, if a person pays more for faster delivery, a priority may be given 


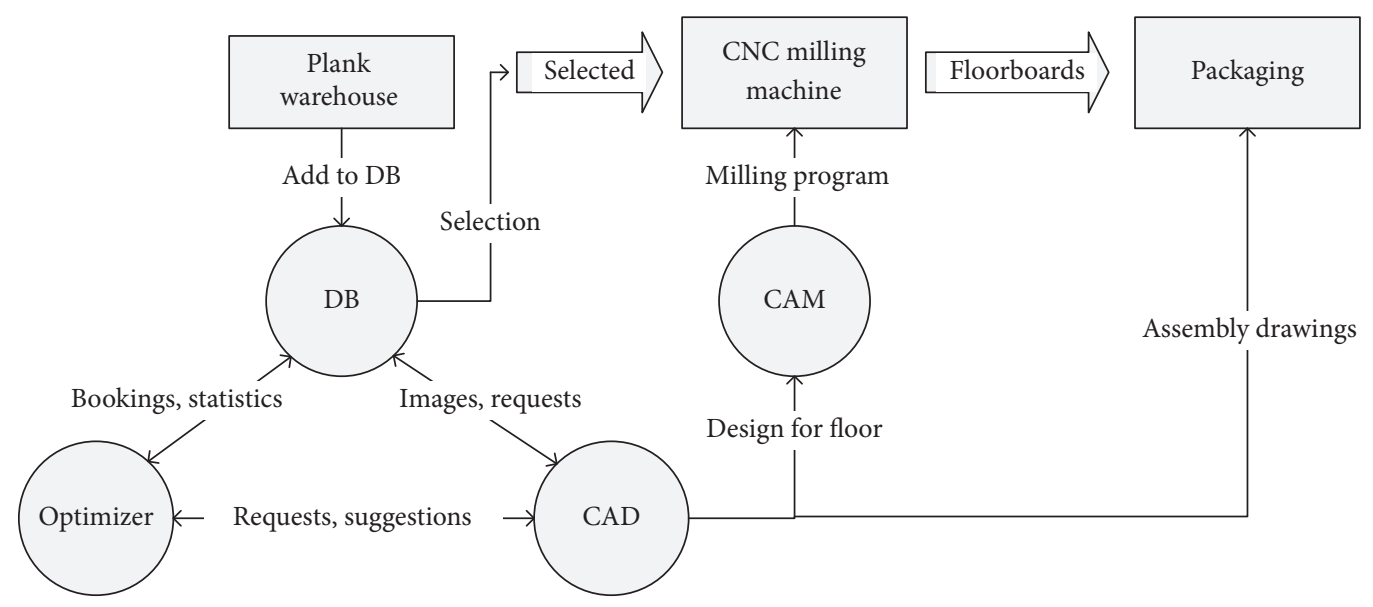

FIGURE 10: The production process of curved floor [8].
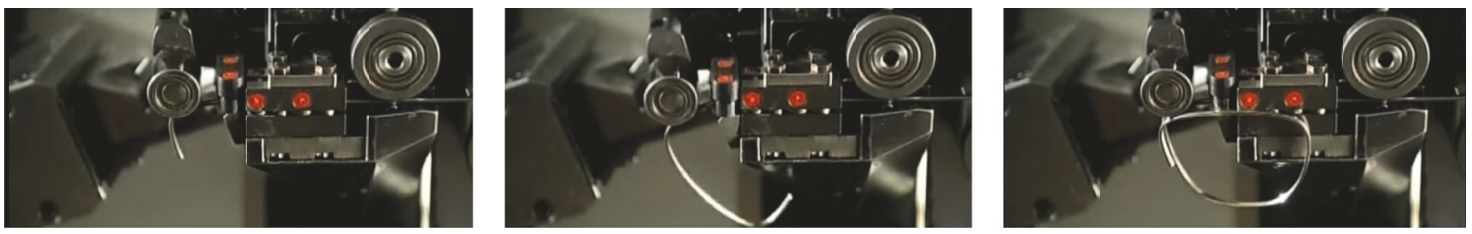

FIGURE 11: The warping process of eyeglass raw material.

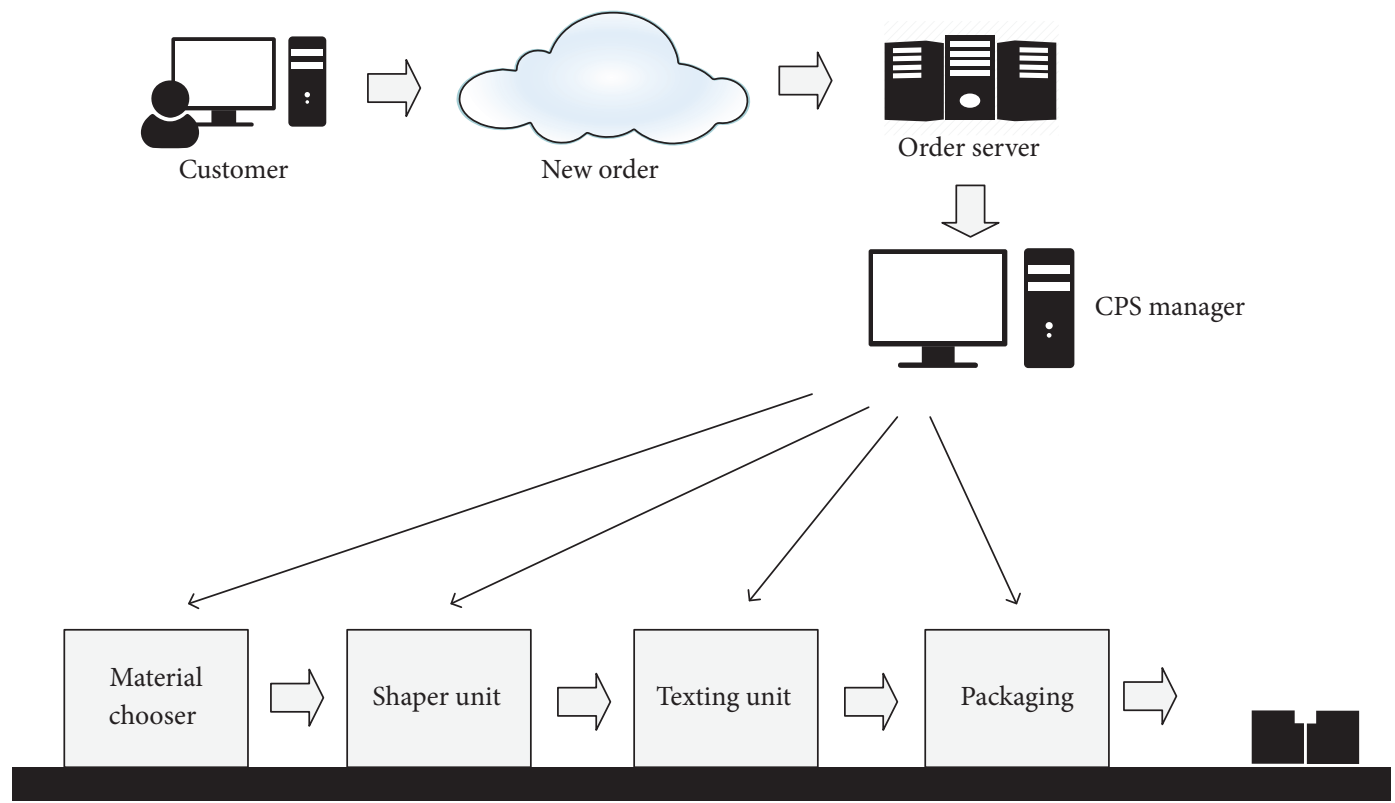

Figure 12: A sample about the eyeglass frames for proposed method.

to his/her process. And, this may provide extra revenues for firms.

Lanyman is a German mass-customized keychain company. Their prices and shipping times are given in Table 1. A person in Germany must pay $8.90 €$ to buy a personalized keychain. This is not problem for customers, because standard keychains are at similar prices. But the waiting time may be deterrent factor. While a person buys standard keychain at markets immediately, he/she must wait at least 5 days to get customized one. Considering the shipment time is about 23 days, the product needs 3-5 days to be produced. It is too much and probably more time is spent on operators [17]. If we remove them, we can produce the product much earlier. Considering there are 1000 orders and an order is produced in 30 seconds, so 30000 seconds is needed to produce all orders. It is about 8.5 hours, and it means the orders are 
TABLE 1: lanyman.com shipping and handling conditions [17].

\begin{tabular}{lcc}
\hline Country & Cost $(€)$ & Waiting time (day) \\
\hline Bulgaria & 9.65 & $9-12$ \\
Germany & 4.60 & $5-7$ \\
Denmark & 8.60 & $7-9$ \\
Finland & 24.70 & $10-13$ \\
\hline
\end{tabular}

produced in shorter than one day. Shipments are done at the end of the day, so an order needs about 1 day to be produced. When we compare it with the current method, the proposed approach is $60-80 \%$ faster. The other companies may not wait for production so much as this. So the gain changes from case to case.

Machines in a factory work according to pipeline method. So when a machine working on one product, another machine works on probably another product. This makes the system responsible for managing all machines simultaneously one by one. For example, in our sample, when raw material is selected for $n$th order, shaping operation is working for $n+1$ th order. At the end of the production line, order is produced and packaged and is ready to ship. Because we know each product's identical information, the location where the produced order will be shipped is also known. So the production can be shipped easily by the autonomy shipping vehicles which are a part of smart city. There is autonomy shipping system with drones for near places, within about 30 minutes, but it is seen possible for far places thanks to autonomy transport in near future.

\section{Conclusions}

Mass customization is one of the preferred production models today because of its structure which makes possible to produce specialized products with low cost. However, because of its order-to-product architecture, it needs more time for delivery than mass-production model. The time for ordering, manufacturing, and shipping and the time between the steps reduce mass customization's appeal. This paper presented an approach which reduces the elapsed time with integration of these steps in a secure way. For this aim, cyber city components and Industry 4.0 are combined in cyberphysical system infrastructure, so that the order, production, and delivery steps can be performed automatically and faster.

The problems occurred when trying to integrate the two different terms, such that security and efficiency are handled. An order server, which takes order from customers and transfer it to factory environment when completed, is used as middle layer between smart city and Industry 4.0 layers. It makes the system more secure against Internet attacks. As it is not efficient way to make the machines working in factory for a few orders, they should be started according to an algorithm that optimizes the parameters.

Speeding up the process of mass customization makes it more appealing and more preferable for customers. Producers will take into account the demands of customers inevitably. And the count of factories using Industry 4.0, which is more energy efficient, will increase. This contribute energy saving and will have an additive positive effect to economy and ecosystem also.

\section{Conflicts of Interest}

The authors declare that there are no conflicts of interest regarding the publication of this article.

\section{Acknowledgments}

This work was supported by Scientific Research Projects Coordination Unit of Firat University, Project no. MF.17.09.

\section{References}

[1] C. Manville, G. Cochrane, J. Cave et al., "Mapping Smart Cities in the EU , European Parliament's Committee," Tech. Rep., 2014.

[2] A. Cocchia, "Smart and Digital City: A Systematic Literature Review," in Part of the series Progress in IS, pp. 13-43, Springer International Publishing, 2014.

[3] P. Neirotti, A. De Marco, A. C. Cagliano, G. Mangano, and F. Scorrano, "Current trends in smart city initiatives: Some stylised facts," Cities, vol. 38, pp. 25-36, 2014.

[4] H. Yetis, M. Baygin, and M. Karakose, "An investigation for benefits of cyber-physical systems in higher education courses," in Proceedings of the 15th International Conference on Information Technology Based Higher Education and Training, ITHET 2016, Istanbul, Turkey, September 2016.

[5] S. Gupta and S. K. Jain, "A literature review of lean manufacturing," International Journal of Management Science and Engineering Management, vol. 8, no. 4, pp. 241-249, 2013.

[6] R. Petrolo, V. Loscri, and N. Mitton, "Cyber-Physical Objects as Key Elements for a Smart Cyber-City," in Management of Cyber Physical Objects in the Future Internet of Things, Internet of Things, pp. 31-49, Springer International Publishing, 2016.

[7] S. Ali, S. B. Qaisar, H. Saeed, M. F. Khan, M. Naeem, and A. Anpalagan, "Network challenges for cyber physical systems with tiny wireless devices: A case study on reliable pipeline condition monitoring," Sensors (Switzerland), vol. 15, no. 4, pp. 7172-7205, 2015.

[8] A. Ojamaa, V. Kotkas, M. Spichakova, and J. Penjam, "Developing a lean mass customization based manufacturing," in Proceedings of the 2013 16th IEEE International Conference on Computational Science and Engineering, CSE 2013, pp. 28-33, Sydney, Australia, December 2013.

[9] H. Yetiş and M. Karaköse, "Adaptive vision based condition monitoring and fault detection method for multi robots at production lines in industrial systems," International Journal of Applied Mathematics, Electronics and Computers, vol. 4, no. 1, pp. 271-271, 2016. 
[10] R. Baçzyk and A. Kasiński, "Visual simultaneous localisation and map-building supported by structured landmarks," International Journal of Applied Mathematics and Computer Science, vol. 20, no. 2, pp. 281-293, 2010.

[11] G. Vegah, U. Wajid, and B. Adebisi, "Smart-agent system for flexible, personalised transport service," The Journal of Engineering, pp. 1-11, 2016.

[12] J. Kolodziej and F. Xhafa, "Modern approaches to modeling user requirements on resource and task allocation in hierarchical computational grids," International Journal of Applied Mathematics and Computer Science, vol. 21, no. 2, pp. 243-257, 2011.

[13] Krebson Security, "Hacked Cameras, DVRs Powered Today's Massive Internet Outage," https://krebsonsecurity.com/2016/10/ hacked-cameras-dvrs-powered-todays-massive-internet-outage/, Oct. 2016

[14] M. Hall-May, M. Surridge, and R. Nossal-Tüyeni, "Resilient critical infrastructure management with a service oriented architecture: A test case using airport collaborative decision making," International Journal of Applied Mathematics and Computer Science, vol. 21, no. 2, pp. 259-274, 2011.

[15] S. T. Zargar, J. Joshi, and D. Tipper, "A survey of defense mechanisms against distributed denial of service (DDOS) flooding attacks," IEEE Communications Surveys \& Tutorials, vol. 15, no. 4, pp. 2046-2069, 2013.

[16] G. Sen Gupta, M. Ooi, S. Khan et al., "Assistive technology for relieving communication lumber between hearing/speech impaired and hearing people," The Journal of Engineering, pp. $1-12,2014$.

[17] P. Coletti and T. Aichner, Mass Customization, Springer Berlin Heidelberg, Berlin, Germany, 2011.

[18] R. G. Hollands, "Will the real smart city please stand up?" City, vol. 12, no. 3, pp. 303-320, 2008.

[19] A. Coe, G. Paquet, and J. Roy, "E-governance and smart communities: a social learning challenge," Social Science Computer Review, vol. 19, no. 1, pp. 80-93, 2001.

[20] M. Karakose, "Reinforcement learning based artificial immune classifier," The Scientific World Journal, vol. 2013, Article ID 581846, 7 pages, 2013. 


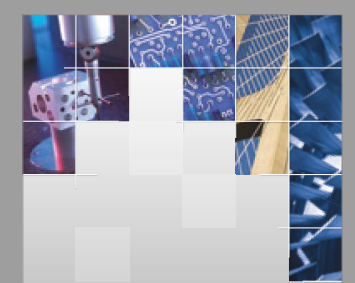

\section{Enfincering}
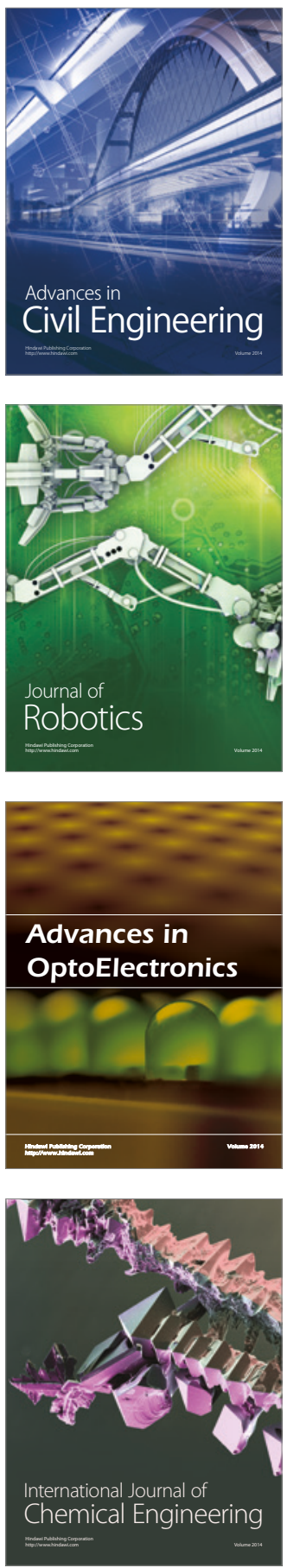

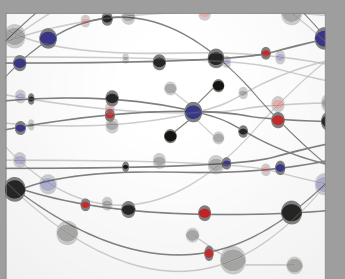

The Scientific World Journal

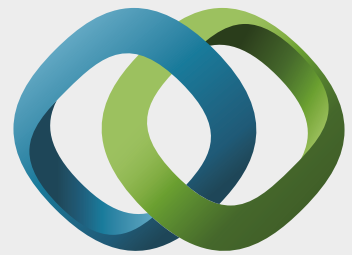

\section{Hindawi}

Submit your manuscripts at

https://www.hindawi.com
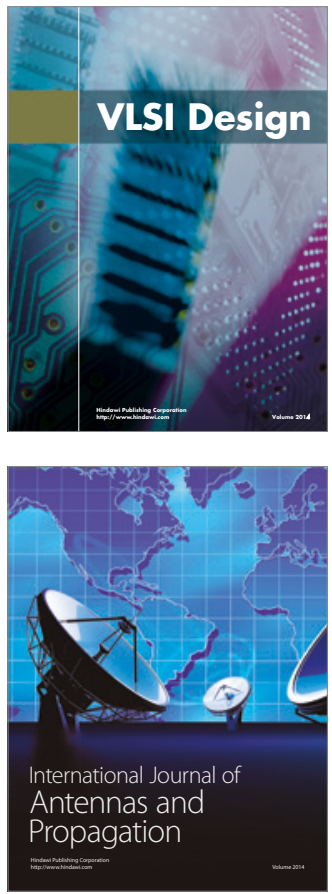

\section{Rotating}

Machinery
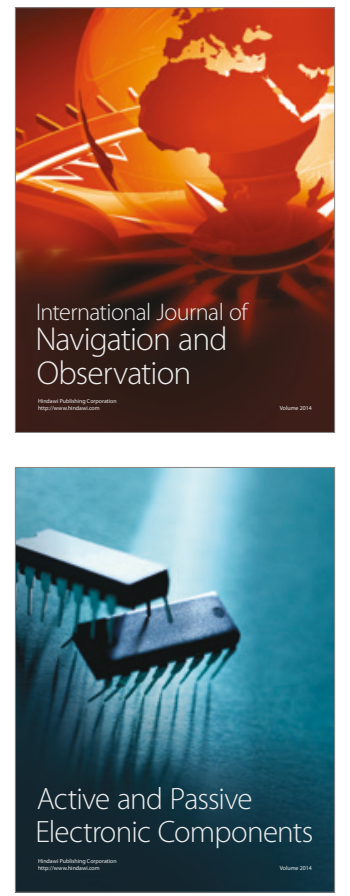
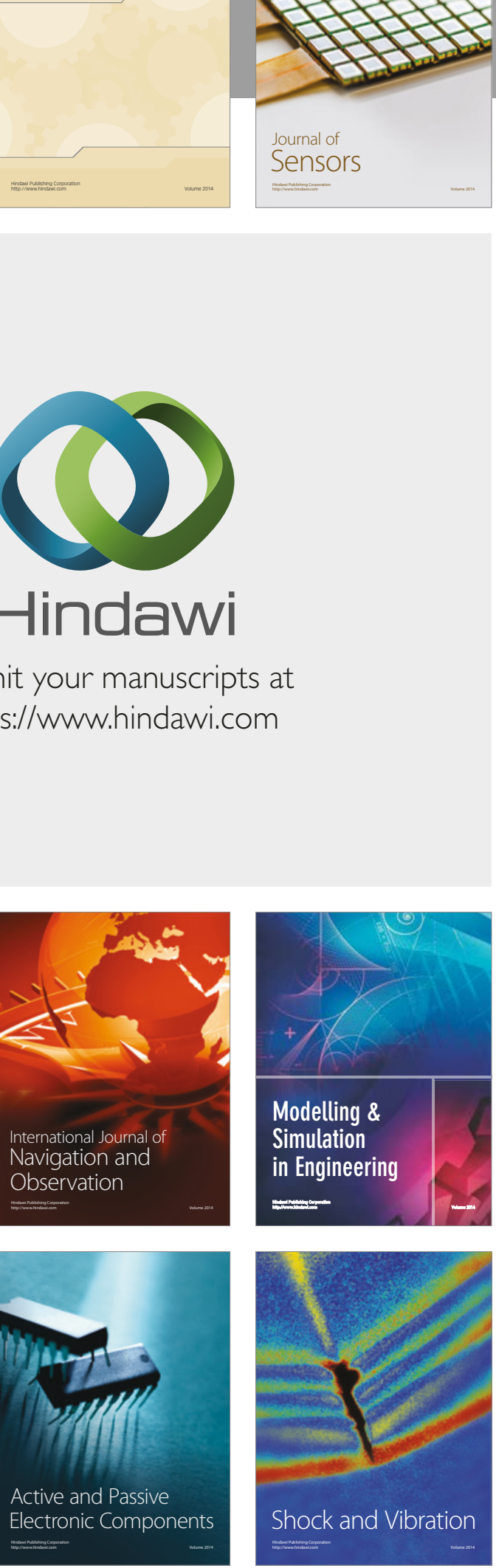
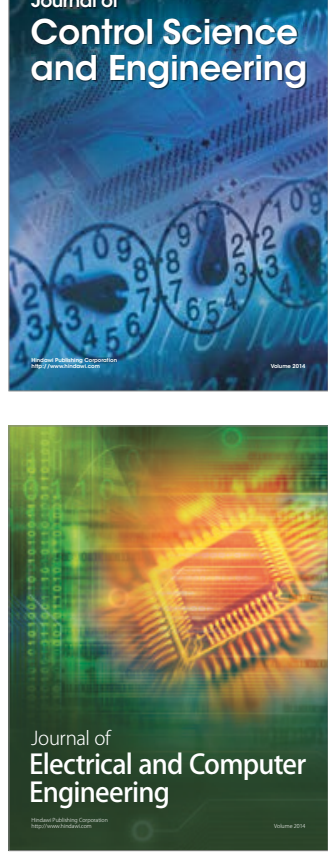

Distributed

Journal of

Control Science

and Engineering
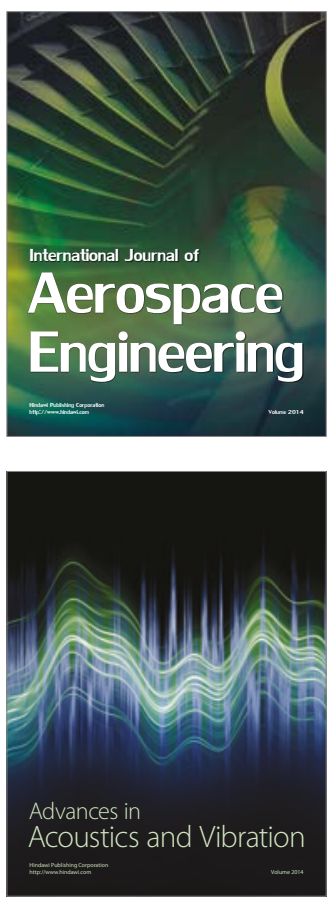

Sensor Networks 